\title{
Metallurgy and material|s \\ Operational conditions \\ of an electrostatic separator for concentrate copper from electronic waste \\ http://dx.doi.org/10.1590/0370-44672017710159
}

\section{Fernando Hamerski}

http://orcid.org/0000-0003-2021-798X

Doutorando

Universidade Federal do Rio Grande do Sul - UFRGS

Programa de Pós-Graduação em Engenharia de

Minas, Metalúrgica e de Materiais

Porto Alegre - Rio Grande do Sul - Brasil

fhamerski@gmail.com

\section{Dillan Passos Bernardes}

Graduando em Engenharia de Materiais

Universidade Federal do Rio Grande do Sul - UFRGS

Departamento de Materiais

Escola de Engenharia, Curso de Engenharia de Materiais

Porto Alegre - Rio Grande do Sul - Brasil

dillanbernardes@gmail.com

\section{Hugo Marcelo Veit}

Professor

Universidade Federal do Rio Grande do Sul - UFRGS

Programa de Pós-Graduação em Engenharia de

Minas, Metalúrgica e de Materiais

Porto Alegre - Rio Grande do Sul - Brasil

hugo.veit@ufrgs.br

\section{Introduction}

Population growth coupled with increased purchasing power and rapid technological development are directly related to the generation of Waste Electrical and Electronic Equipment (WEEE), since the time elapsing before users upgrade to newer devices is decreasing (Veit et al., 2005; Veit et al., 2006; Huang et al., 2009; Ongondo, et al., 2011; Hadi et al. 2015a). Electronic waste is composed of several substances, many of them economically interesting and others harmful to the environment, if they are disposed of incorrectly. Generally, they are composed of polymers, ceramics and metals, such as arsenic, cadmium, lead, copper, tin, mercury, nickel and gold, as well as rare earths (Xiu \& Zhang, 2010; Jing-Ying, et al., 2012).

PCBs are an essential part of almost

\begin{abstract}
Interest in recycling for the recovery of valuable substances, such as precious metals from electric and electronic waste has been increasing year after year due to the large amount present in such waste compared to primary sources. There is environmental concern, since the amount of this kind of waste is increasing due to rapid technological advances. This study aimed to test the different operating conditions of an electrostatic separator for the concentration of copper from printer circuit boards (PCB). The PCBs were milled in knife mills and separated according to the difference of granule sizes into two fractions: A $(<0.5 \mathrm{~mm})$; $\mathrm{B}(0.5<\mathrm{B}<1 \mathrm{~mm})$, followed by scaling. Then, the samples were subjected to a magnetic separator for removing the magnetic materials to obtain a concentrate with a higher content of copper. After the magnetic separator, an electrostatic separator was used, where different conditions were employed for each sample: roller rotation (100 and $175 \mathrm{rpm}$ ) and tension (20 and 35 $\mathrm{kV})$. Iron concentrations were observed after the magnetic separator, between 12 and $14.1 \%$ for the A fractions and $10.3-11.4 \%$ for the B fractions. After the electrostatic separator, the results for the A samples showed that the concentration of copper varies between 17.5 and $51.1 \%$, with the highest concentration obtained through the use of $100 \mathrm{rpm}$ (roller rotation) and $35 \mathrm{kV}$ (voltage). For the B samples, the variation was between 6.4 and $40.5 \%$. For both particle sizes, the best applied condition was a voltage of $35 \mathrm{kV}$ and a roller rotation of $100 \mathrm{rpm}$.
\end{abstract}

Keywords: electronic waste, electrostatic separator, copper recovery, waste printed circuit board.

all Electrical and Electronic Equipment (EEE) and they consist of a blend of glass fiber, cellulosic fiber reinforced resin and many kinds of metals, as well as brominated flame-retardants (Huang et al., 2009; Hadi, et al., 2015a). The concentration of metals such as $\mathrm{Ag}, \mathrm{Au}, \mathrm{Cu}$ and $\mathrm{Pt}$ is much higher than in their respective primary sources. Therefore, the recycling of PCBs not only matters to the environment but is also desirable because of the recovery of valuable materials (Robinson, 2009; Hadi et al., 2015b).

The recovery/recycling of these metals may involve several processes. Hydrometallurgical and pyrometallurgical routes are the most used, but these processes can generate intense and severe environmental pollution, such as the generation of acidic liquid effluents from hydrometallurgical processes, as well as the release of dioxins and furans from the pyrometallurgical process (Li et al., 2007; Li et al., 2008b).

In this context, mechanical processes are a very interesting alternative, such as pretreatment, in order to obtain fractions that are more concentrated with interesting metals and thereby reduce the financial costs and potential polluting effects of the above processes.

Among the mechanical processes, electrostatic separation (separation of conductive and nonconductive materials) presents an effective method for the concentration of materials with high economic value, such as the copper present in WEEE, especially PCBs (Li et al., 2008a; Li et al., 2008b).

Figure 1 shows a schematic drawing 
of the operation of an electrostatic separator. The materials to be separated are fed at a known speed onto the surface of the grounded roller, where the particles pass through the electric field generated by the

Figure 1

Operating scheme of electrostatic separator (Wu et al., 2009b).

Veit et al. (2005) employed only one operating condition of the electrostatic separator, with a $45 \mathrm{kV}$ of high-voltage in samples below $1 \mathrm{~mm}$. Jiang, et al. (2009b) used synthetic waste with a particle size between 0.3-0.45 mm. In addition, conditions such as feed rate and roll speed were evaluated.

However, the use of PCB waste with fine particles can cause accumulation of dust on the electrode's surface. Due to the electrostatic effects, this phenomenon negatively interferes with the charge distribution

\section{Matherial and methods}

For this study, $8 \mathrm{~kg}$ of PCBs were used from obsolete computers. Reduction of the material to a granulometry smaller than $1 \mathrm{~mm}$ was carried out in two knife mills. Then the material was classified into two particle sizes: $\mathrm{A}(<0.5 \mathrm{~mm})$ and $\mathrm{B}(0.5<\mathrm{B}<1.00 \mathrm{~mm})$. The metal contents present in both fractions were analyzed by the flame atomic absorption technique after digestion in aqua regia of $20 \mathrm{~g}$ samples. electrodes. The conductive and nonconductive particles entering the electric field are subjected to electrostatic induction and ionic bombardment. The conductive particles are quickly discharged to the grounded roller while the nonconductive particles are drawn to the spinning roller and into the holding compartments (Wu et al., 2008, Wu et al., 2009; Li et al., 2008a; Li et al., 2008b).

Nonconductive Particle
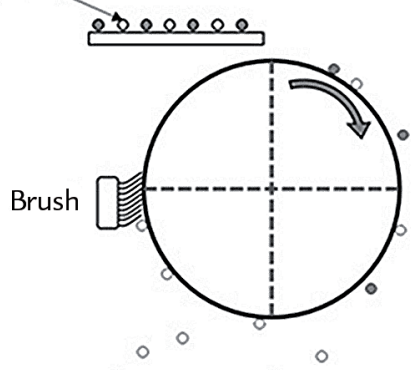

Corona Electrode

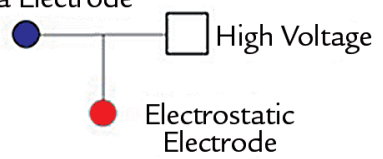

Conductive Particle

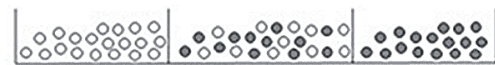

Nonconductive Middling Conductive Products Products Products of the electric field and its distribution in the space between the electrode and the roller, thus weakening the electric field. So, the charging process and electrical force acting on the particle waste are weakened and this can cause an increase of middling products (mixture of conductive and non-conductive materials). Thus, the accumulation of dust on the electrode's surfaces is disadvantageous in the metal concentration process by electrostatic separators, which justified the use of larger particles of PCB waste.

According to Jiang et al., a high roller speed entails a high production capacity of the electrostatic separator for PCBs waste (Jiang et al. 2009a). However, the influence of roller speeds as well as different values of electric fields were not reported in literature, especially with regard to the use of real PCB waste.

Thus, this study aimed to concentrate copper from PCB waste, previously milled, granulometric and magnetic separated, and evaluating the different high-voltage values and high roll rotation conditions of the electrostatic separator.
The fractions from the particle size separator were quartered into 4 fractions (totaling 8 samples). These samples were subjected to a dry roller magnetic separator with an applied 1300 Gauss. After the magnetic separator, two fractions of each sample were obtained: magnetic $\left(A_{M}\right.$ and $\left.\mathrm{B}_{\mathrm{M}}\right)$ and nonmagnetic $\left(\mathrm{A}_{\mathrm{NM}}\right.$ and $\left.\mathrm{B}_{\mathrm{NM}}\right)$. The magnetic fractions were analyzed chemically, while the nonmagnetic frac-

tions were subjected to the electrostatic separation process.

Among the possible variables of operation of the electrostatic separator, the electrodes were kept fixed, following the configuration: Ionizing Electrode Angle $-80^{\circ}$, its distance from rotor $25 \mathrm{~cm}$; Static and Electrode Angle 52, $5^{\circ}$, its distance from rotor $-25 \mathrm{~cm}$. The velocity of the grounded roller and voltage used are shown in Table 1.

\begin{tabular}{c|c|c} 
Sample & Roller Velocity $(\mathrm{RPM})$ & Voltage $(\mathrm{kV})$ \\
\hline $\mathrm{A} 1_{\mathrm{NM}}$ & 100 & 20 \\
\hline $\mathrm{A} 2_{\mathrm{NM}}$ & 175 & 20 \\
\hline $\mathrm{A} 3_{\mathrm{NM}}$ & 100 & 35 \\
\hline $\mathrm{A} 4_{\mathrm{NM}}$ & 175 & 35 \\
\hline $\mathrm{B} 1_{\mathrm{NM}}$ & 100 & 20 \\
\hline $\mathrm{B} 2_{\mathrm{NM}}$ & 175 & 20 \\
\hline $\mathrm{B} 3_{\mathrm{NM}}$ & 100 & 35 \\
\hline $\mathrm{B} 4_{\mathrm{NM}}$ & 175 & 35 \\
\hline
\end{tabular}

Table 1

Operating variables applied in the electrostatic separator.

After the electrostatic separator, two fractions were obtained: conductive $\left(\mathrm{A}_{\mathrm{C}}, \mathrm{B}_{\mathrm{C}}\right)$ and nonconductive $\left(\mathrm{A}_{\mathrm{MIX}}, \mathrm{B}_{\mathrm{MIX}}\right)$. 


\section{Results and discussion}

\subsection{Granulometric separation}

The samples were analyzed chemically after grading for qualitative and quan-

Table 2

PCB characterization from $A$ and $B$ particle size.

It is important to note the high copper and iron contents found in both fractions. However, in comparison to ores, only the copper content is attractive for recovery from the economic point of view. The A fraction presented $13.3 \%$ and the B, $19.6 \%$ of

\subsection{Magnetic separation}

With the previously separated samples, the magnetic separation was

Figure 2

Mass percent of magnetic and nonmagnetic material of sample.

The percentage of magnetic material of the A samples ranged from 52 (A3) to $70.6 \%$ (A2). For the B samples, the values ranged from 5.5 (B3) to $7.72 \%$ (B2). In all the A samples (A1,..A4) most of the material was

Figure 3

Chemical analysis of magnetic samples.

titative characterization of the metals in the

PCBs. The results are shown in Table 2.

\begin{tabular}{c|c|c} 
& \multicolumn{2}{|c}{$(\%)$} \\
\hline Metal & A & B \\
\hline $\mathbf{P b}$ & 0.55 & 0.50 \\
\hline $\mathrm{Cu}$ & 13.30 & 19.60 \\
\hline $\mathbf{F e}$ & 5.85 & 1.45 \\
\hline $\mathrm{Ni}$ & 0.37 & 0.26 \\
\hline $\mathbf{Z n}$ & 1.20 & 1.80 \\
\hline
\end{tabular}

copper, levels far above the average found in ores, which according to the British Geological Survey (2007) are between $0.2-1 \%$.

The higher concentration of copper in the $\mathrm{B}$ fraction in relation to the $\mathrm{A}$ fraction is related to the greater difficulty of

performed. In Figure 2, it is possible to observe the percentage of magnetic grinding this metal due to its ductility. In addition, the concentration of lead, which must be taken into account not only for its economic value, but mainly for its harmful effects, should be emphasized if it is disposed of incorrectly.

and nonmagnetic material in each of the samples.

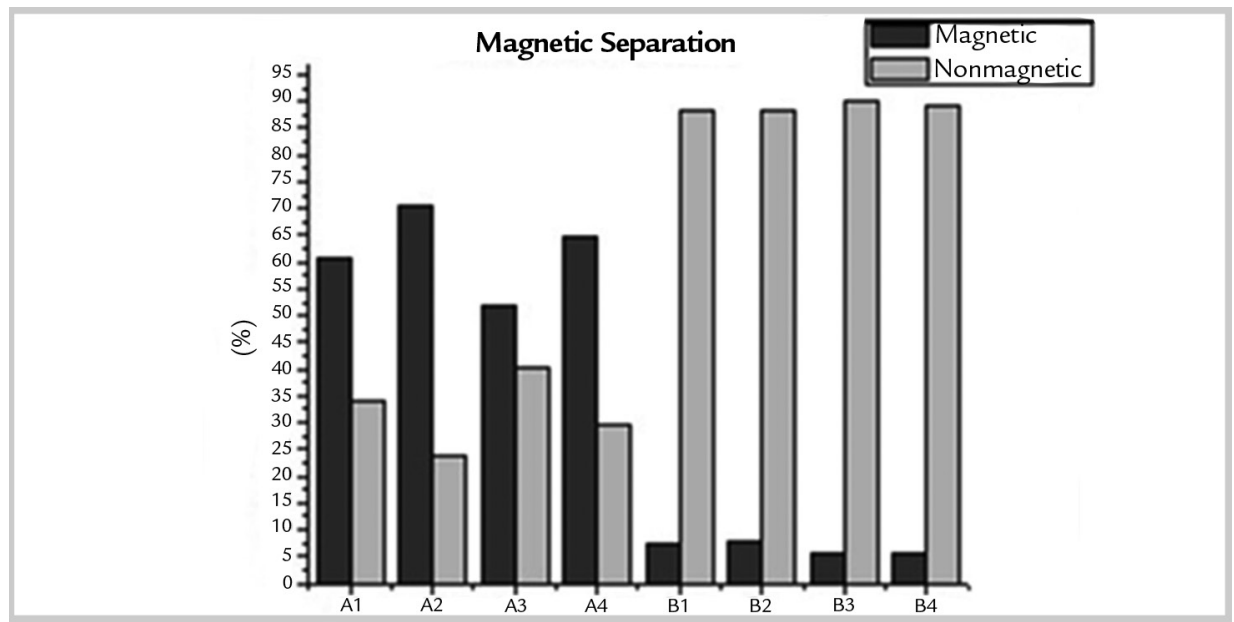

retained in the magnetic fraction and the amount of magnetic material present in the PCBs is less than the other materials (e.g. ceramics, polymers), showing some kind of interference during the process. This can be explained by the susceptibility of the smaller particles entering a magnetic field to be carried along with the magnetic material. Figure 3 shows the copper and iron contents after chemical analysis of the magnetic fractions.

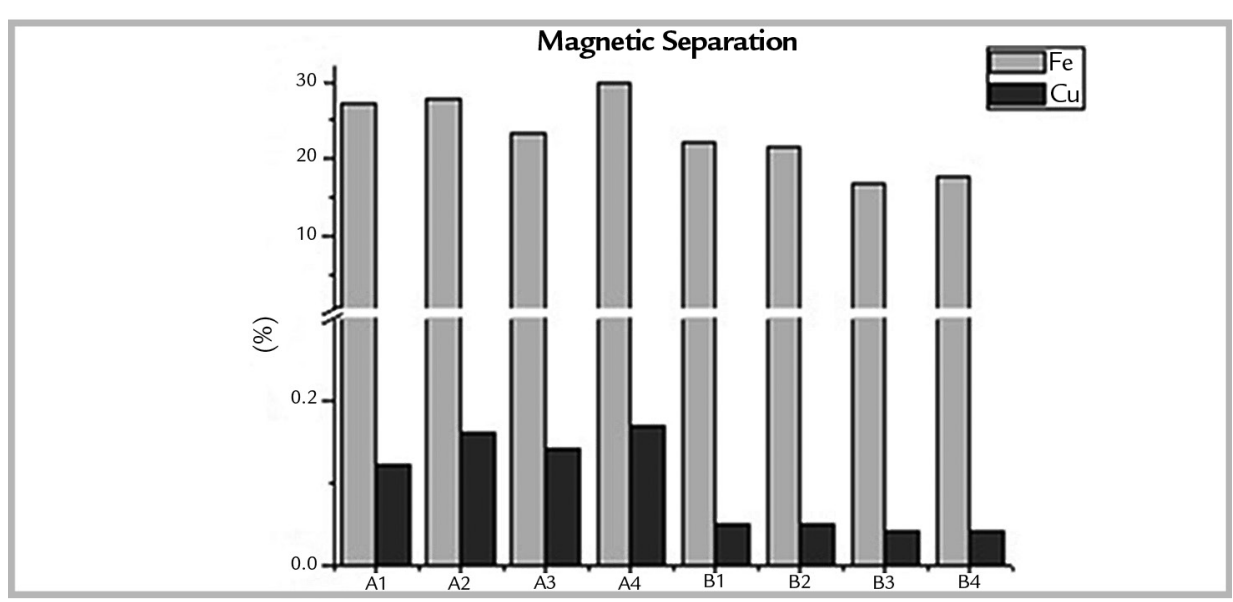


The amounts of iron (magnetic) and copper (conductive) after magnetic separation, seen in Figure 3, shows that for the A samples, the variation in concentrations was 27.8 (A2) to $30 \%$ (A4) of iron. In the B samples, the iron concentrations varied between 16.9 (B3) and 22.2\% (B1). For both particle sizes, extremely low amounts of copper retained in the magnetic fractions are observed. It is important not to retain

\subsection{Electrostatic separation}

The nonmagnetic samples were submitted to the electrostatic separator, generating two fractions named conductive and mixed. In Figure 4, the fractions the copper in this fraction, since the purpose of using the magnetic separator is precisely to remove the magnetic material (especially iron) and leave the nonmagnetic fraction that has a higher concentration of copper and is purer for later use in the electrostatic separator. The main problem associated with magnetic separation lies in the agglomeration of the particles, which can result in drag/attraction of

of the materials obtained after electrostatic separation are shown. The flowchart (Fig. 5) shows the copper concentration percentages in the conducting samples.

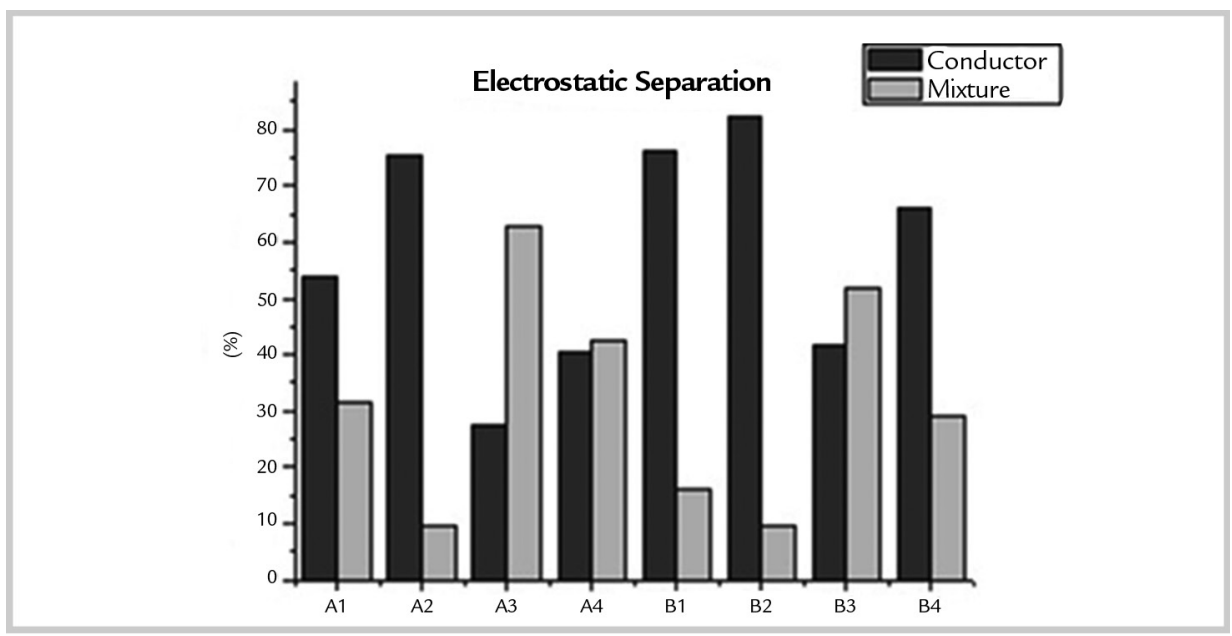

The amounts of conductive and mixed (nonconductive) materials after the electrostatic separator show variations between samples (Fig. 4). In the A samples, the variation was between 27.3 (A3) and $75.3 \%$ (A2). In the B samples, the amount of conductor material obtained was 41.8 (B3) $-82.4 \%$ (B2). Each sample was

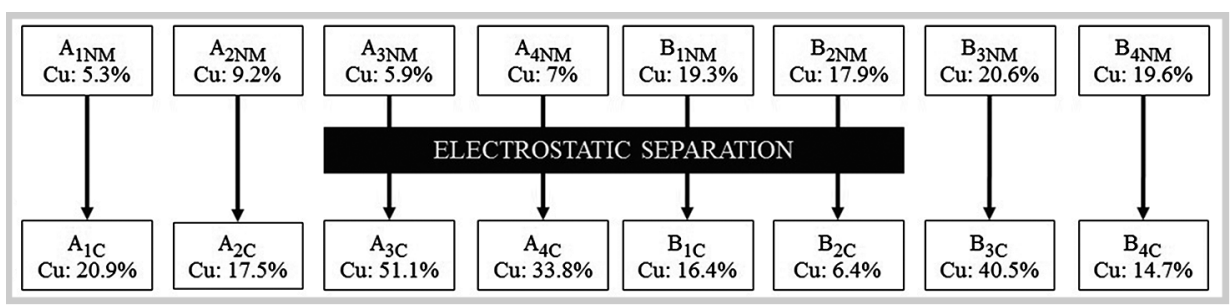

Observing the flowchart (Fig. 5) with the quantities of concentrated copper, the A samples present concentrations higher than the B samples. Samples $A 3_{C}$ and $A 4_{C}$ were subjected to the same applied stress $(35 \mathrm{kV})$, differing only in the roller speed, 100 and $175 \mathrm{rpm}$ respectively. There are, at least, two possible factors influencing the variance between the sample concentrations. One of the factors is related to the roller speed, i.e., when the roller speeds faster, the waste particles are exposed to the electric field for a shorter space of time. The second factor, also known as "bonding effect" occurs when the material layer in the feed chute is thick enough and the particles located at the bottom of this layer are not influenced by the electrical field. Both factors could have a negative effect on the operation of the electrostatic separator. The samples with lower copper concentration were submitted to a lower tension $(20 \mathrm{kV})$, but with the same roller velocities as the other samples. However, as shown in the previous samples, the roller speed has an important relevance in the electrostatic separation process. non-ferrous materials together with the ferrous materials (Hadi et al., 2015a). The increase of copper in the magnetic fractions is also associated with the applied magnetic field; that is to say, if the magnetic field is too high, this metal can be attracted to the magnetic fraction (Callister Jr., 2002; Yoo et al., 2009). However, in the results presented, none of these factors significantly influenced the separation performed.

Copper has been chosen as a metal of interest, as it has high conductive properties, has a high economic value and is found in great quantities in PCBs.

Figure 4

Mass percentage of conductive and mixed material.

submitted to different conditions. It is possible to observe that there is a higher concentration of conductor material in the B samples.

Figure 5

Flowchart of copper concentration.

As for the applied voltage, it is evident that this is the most influential factor for the copper concentration between the samples. Looking at samples $\mathrm{A} 3_{\mathrm{C}}$ and $\mathrm{A} 1_{\mathrm{C}}$ with the same roller rotation, the difference in copper concentration is $30 \%$. Between the highest voltage samples, the difference drops to $16 \%$. For this reason, the use of higher tension is justified.

In relation to the $\mathrm{B}$ samples, the copper concentration was also efficient, but with higher percentage variations. The electrostatic separator conditions were the same as those of the aforemen- 
tioned samples.

Copper concentrations in the samples ranged from $6.4 \%\left(B 2_{\mathrm{C}}\right)$ to $40.5 \%$ $\left(\mathrm{B} 3_{\mathrm{C}}\right)$. Samples $\mathrm{B} 3_{\mathrm{C}}$ and $\mathrm{B} 4_{\mathrm{C}}$ were subjected to the same applied stress, varying the roller rotation $(100-175 \mathrm{rpm})$ and the best result was obtained with the lowest rotation. The same behavior is observed for the samples with lower voltage, $\mathrm{B} 1_{\mathrm{C}}$ and $\mathrm{B} 2_{\mathrm{C}}$, where the best result between

\section{Conclusions}

The large amount of copper present in PCB waste justifies studies to increase the concentration of this metal by environmental eco-friendly, simpler, and lower cost processes such as electrostatic separation before hydrometallurgical and pyrometallurgical routes.

In addition, it has been found that the simple conditions in the electrostatic separator have a great influence on the copper concentration from milled PCBs. For both particle sizes, the best condition

\section{Aknowledgements}

The authors thank the National Counsel of Technological and Scientific these two samples was obtained with the lowest rotation $\left(\mathrm{B} 1_{\mathrm{C}}\right)$.

These results show the extreme importance of studying the fundamental and practical aspects of the electrostatic separator. Conditions such as the applied voltage and rotational speed of the grounded roller, even under easy adjustment conditions, show great differences in the copper concentration from secondary sources such as PCBs. A good example of this is to note that the best condition applied for both particle sizes in this work is condition 3, that is, $35 \mathrm{kV}$ of applied voltage, with rotation of the grounded roller of $100 \mathrm{rpm}$. In addition, the use of known granulometry is fundamental, as each particle size reacts differently to applied stresses (Jiang et al., 2009; Wu et al., 2008a). applied to the electrostatic separator was $35 \mathrm{kV}$ of applied voltage and $100 \mathrm{rpm}$ of roller rotation. Compared to samples where the applied voltage was $20 \mathrm{kV}$ $\left(\mathrm{A} 1_{\mathrm{C}}-\mathrm{B} 1_{\mathrm{C}}\right)$, the difference of the copper concentration is approximately $30 \%$ more for the $\mathrm{A} 3{ }_{\mathrm{C}}$ sample and $24.00 \%$ more for $\mathrm{B} 3{ }_{\mathrm{C}}$. In general, approximately $51 \%$ of the copper in sample $\mathrm{A} 3_{\mathrm{C}}$ and $40 \%$ in $\mathrm{B} 3$ could be concentrated. It was also observed that the particles $(\mathrm{A}<0.5$ $\mathrm{mm}$ ) showed accumulation on electrodes, interfering in the electric field.

Generally to obtain satisfactory results in terms of a large-scale process, the use of higher roller speeds would be better, because the time of materials in the zone of intense electric field decreases. However, in contrast, the results obtained in this study with high roller speeds show the worse results, probably because the particles suffer less interference from the electric field, and the result is a higher amounts of copper in the intermediate fractions.
Development (CNPq) and Coordination for the Improvement of Higher
Education Personnel (CAPES) for financial support.

\section{References}

BRITISH GEOLOGICAL SURVEY. Natural Environmental Research Council - Copper. 2007. Available in <https://www.bgs.ac.uk/mineralsuk/statistics/mineralProfiles.html> Accessed in: 30/04/2017.

CALLISTER JR., W. D. Ciência e engenharia de materiais: uma introdução. (5 ed.). Rio de Janeiro: Editora LTC, 2002. 256 p.

HADI, P. et al. Waste printed circuit board recycling techniques and product utilization. Honk Kong. Journal of Hazardous Materials, v. 283, p. 234-243, 2015 a.

HADI, P. et al. Toward environmentally-benign utilization, of nonmetallic fraction of waste printed circuit boards as modifier and precursor. Waste Management, v. 35, p. 236-246, 2015b.

HUANG, K., GUO, J., XU, Z. Recycling of waste printed circuit boards: A review of current technologies and treatment status in China. Journal of Hazardous Materials, v. 165, p. 399-408, 2009.

JIANG, W., JIA, L., ZHEN-MING, X. A New two-roll electrostatic separator for recycling of metals and nonmetals from waste printed circuit board. Journal of Hazardous Materials. v. 161, p. 257-262, 2009a.

JIANG, W. et al. Impact of nonconductive powder on electrostatic separation for recycling crushed waste printed circuit board. Journal of Hazardous Materials, v. 164, P. 1352-1358, 2009b.

JING-YING, L., XIU-LI, X., WEN-QUAN, L. Thiourea leaching gold and silver from the printed circuit boards of waste mobile phones. Waste Management, v. 32, p. 1209-1212, 2012.

LI, J., XU, Z., ZHOU, Y. Application of corona discharge and electrostatic force to separate metals and nonmetals from crushed particles of waste printed circuit boards. Shangai, China. Journal of Electrostatics, v. 65, p. 233-238, 2007.

LI, J., XU, Z., ZHOU, Y. Theoretic model and computer simulation of separating mixture metal particles from waste printed circuit board by electrostatic Separator. Shangai, China. Journal of Hazardous Materials, v. 153, p. 1308-1313, 2008a. 
LI, J. et al. Optimizing the operation parameters of corona electrostatic Separation for recycling waste scraped printed circuit boards by computer simulation of electric field. Shangai, China. Journal of Hazardous Materials, v. 153, p. 269-275, 2008b.

ONGONDO, F. O., WILLIAMS, I. D., CHERRET, T. J. How are WEEE doing? A global review of the management of electrical and electronic wastes. Waste Management, v. 31, p. 714-730, 2011.

ROBINSON, B. H. E-waste: An assessment of global production and environmental impacts. Canterbury, New Zeeland. Science of the Total Environment, v. 408, p. 183-191, 2009.

VEIT, H. M. et al. Utilization of magnetic and electrostatic separation in the recycling of printed circuit boards scrap. Porto Alegre, Brazil. Waste Management, v. 25, p. 67-74, 2005.

VEIT, H. M. et al. Recovery of copper from printed circuit boards scraps by mechanical processing and electrometallurgy. Porto Alegre, Brazil. Journal of Hazardous Materials, v. B137, p. 1704-1709, 2006.

XIU, F-R., ZHANG, F-S. Materials recovery from waste printed circuit boards by supercritical methanol. Journal of Hazardous Materials, v. 178, p. 628-634, 2010.

YOO, J.-M. et al. Enrichment of the metallic components from waste printed circuit boards by a mechanical separation process using a stamp mill. Waste Management, v. 29, p. 1132-1137, 2009.

WU, J., LI, J., XU, Z. Electrostatic separation for multi-size granule of crushed printed circuit board waste using two-roll separator. Shangai, China. Journal of Hazardous Materials, v. 159, p. 230-234, 2008.

WU, J. et al. Impact of nonconductive powder on electrostatic separation for recycling crushed waste printed circuit board. Shangai, China. Journal of Hazardous Materials, v. 164, p. 1352-1358, 2009.

Received: 31 October 2017 - Accepted: 12 April 2018.. 